\title{
The osmotic stress response and virulence in pyelonephritis isolates of Escherichia coli: contributions of RpoS, ProP, ProU and other systems
}

\author{
Doreen E. Culham, ${ }^{1}$ Annie Lu, ${ }^{1,3}$ Miki Jishage, ${ }^{2}$ Karen A. Krogfelt, ${ }^{3}$ \\ Akira Ishihama $^{2}$ and Janet M. Wood ${ }^{1}$
}

1 Department of Microbiology, University of Guelph, Guelph, Ontario, N1G 2W1, Canada

2 Department of Molecular Genetics, National Institute of Genetics, Mishima, Shizuoka-ken 411, Japan

3 Department of Gastrointestinal Infections, Statens Serum Institut, DK2300 Copenhagen, Denmark

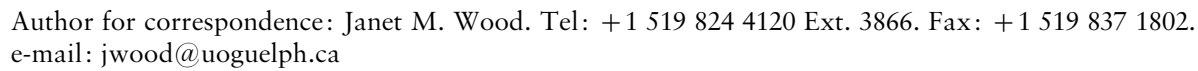

Trehalose synthesis (RpoS-dependent) and betaine uptake mediated by transporters ProP and ProU contribute to the osmotolerance of Escherichia coli K-12. Pyelonephritis isolates CFT073 and HU734 were similar and diminished in osmotolerance, respectively, compared to $E$. coli K-12. The roles of RpoS, ProP and ProU in osmoregulation and urovirulence were assessed for these isolates. Strain HU734 expressed an RpoS variant which had low activity and a Cterminal extension. This bacterium accumulated very little trehalose and had poor stationary-phase thermotolerance. For E. coli CFT073, introduction of an rpoS deletion impaired trehalose accumulation, osmotolerance and stationaryphase thermotolerance. The rpos defects accounted for the difference in osmotolerance between these strains in minimal medium of very high osmolality (1.4 mol $\left.\mathrm{kg}^{-1}\right)$ but not in medium of lower osmolality $\left(0.4 \mathrm{~mol}^{\mathrm{kg}}{ }^{-1}\right)$. The slow growth of both pyelonephritis isolates in high-osmolality medium was stimulated by glycine betaine (GB) and deletion of proP and/or proU impaired GB uptake. An HU734 derivative lacking both proP and proU retained osmoprotective GB uptake activity that could be attributed to system BetU, which is not present in strain K-12 or CFT073. BetU transported GB $\left(K_{m}, 22 \mu \mathrm{M}\right)$ and proline betaine. High-osmolality human urine $\left(0.92 \mathrm{~mol} \mathrm{^{-1 }}\right)$ included membrane-permeant osmolyte urea (0.44 M) plus other constituents which contributed an osmolality of only approximately $0.4 \mathrm{~mol} \mathrm{~kg}^{-1}$. Strains HU734 and CFT073 showed correspondingly low GB uptake activities after cultivation in this urine. Deletion of proP and proU slowed the growth of $E$. coli HU734 in this high-osmolality human urine (which contains betaines) but had little impact on its colonization of the murine urinary tract after transurethral inoculation. By contrast, deletion of rpos, proP and proU had no effect on the very rapid growth of CFT073 in high-osmolality urine or on its experimental colonization of the murine urinary tract. Rpos-dependent gene expression is not essential for growth in human urine or colonization of the murine urinary tract. Additional osmoregulatory systems, some not present in E. coli K-12 (e.g. BetU), may facilitate growth of pyelonephritis isolates in human urine and colonization of mammalian urinary tracts. The contributions of systems ProP and ProU to urinary tract colonization cannot be definitively assessed until all such systems are identified.

Keywords: osmoregulation, glycine betaine, trehalose, UPEC

Abbreviations: GB, glycine betaine; UPEC, uropathogenic Escherichia coli.

The GenBank accession numbers for the DNA sequences of the rpoS loci in E. coli strains HU734 and CFT073 are AF275947 and AF270497, respectively. 


\section{INTRODUCTION}

Urinary tract infection provides a useful model for the relationship between bacterial stress tolerance and virulence because the urinary tract imposes multiple physicochemical stresses on colonizing bacteria. They include variations in $\mathrm{pH}$ (range approximately 5-8), osmolality and urea concentration. Our goal is to define the osmoregulatory mechanisms of uropathogenic Escherichia coli (UPEC) and their contributions to virulence.

High urea levels and fluctuating osmolality distinguish the urinary tract from most other mammalian systems. Although the osmolality of urine from humans with a normal diet and fluid intake is in the range $0.5-0.8 \mathrm{~mol}$ $\mathrm{kg}^{-1}$, urinary osmolality may vary from approximately $0.04 \mathrm{~mol} \mathrm{~kg}^{-1}$ to $1.4 \mathrm{~mol} \mathrm{~kg}^{-1}$ in humans (Altman, 1961; Kunin, 1987; Ross \& Neely, 1983) and up to 3 mol kg-1 in rats and mice (Loeb \& Quimby, 1989; SchmidtNielsen et al., 1983). Urea, the primary contributor to the osmolality of urine and of renal extracellular fluid, can approach concentrations of 0.5 and $1.5 \mathrm{M}$ in human and rat urine, respectively. Inorganic ions are the other major contributors. E. coli strains growing in urine are believed to utilize lactate, amino acids, peptides and $\mathrm{NH}_{4}^{+}$as nutrients (some can also utilize citrate and urea) (Brooks \& Keevil, 1997; Gordon \& Riley, 1992). Thus uropathogens must be urea-resistant and salinity-tolerant. They must mount these stress responses in an environment of variable $\mathrm{pH}$ that includes a mixture of organic nutrients.

E. coli is the primary causative agent for ascending infection of the unobstructed human urinary tract (Kunin, 2000). Multiple osmoregulatory mechanisms with overlapping functions facilitate the survival and growth of E. coli K-12 in media with extreme and/or fluctuating osmolalities (Table 1). While contingent on their availability, the uptake of organic osmoprotectants such as glycine betaine (GB) is more effective in promoting cellular rehydration and growth than the uptake of $\mathrm{K}^{+}$and/or the biosynthesis of trehalose (Wood, 1999). The genomes of natural E. coli isolates vary widely and differ extensively from that of E. coli K-12 (Bergthorsson \& Ochman, 1995, 1998). Thus the osmoregulatory systems present in natural isolates, including UPEC, may differ from those defined using $E$. coli K-12 (Table 1).

Despite its high urea content, fluctuating osmolality and $\mathrm{pH}$, urine supports rapid and extensive growth of $E$. coli, at least under aerobic conditions (Culham et al., 1998; Gordon \& Riley, 1992). Upon demonstrating that GB and proline betaine conferred osmoprotective activity on human urine, Chambers \& Kunin (1987) inferred that osmoregulatory betaine uptake may promote growth in urine and colonization of the human urinary tract by E. coli (Chambers \& Lever, 1996). Neither osmotolerance (Kunin et al., 1992; Peddie et al., 1996) nor the occurrence of betaine transporters ProP and ProU (Culham et al., 1994) is correlated with isolation from the urinary tract for E. coli. Nevertheless, the growth rate of E. coli HU734, an acute pyelonephritis isolate, in high-osmolality human urine was reduced by deletion of the gene encoding osmoregulatory betaine transporter ProP (Culham et al., 1998).

Alternative $\sigma$ factor RpoS mediates the expression of genes implicated in osmotolerance (e.g. ots $A B$, proP), acid tolerance, thermotolerance, oxidative stress and stationary-phase survival for E. coli K-12 and other bacteria (Abee \& Wouters, 1999; Hengge-Aronis, 1996; Ishihama, 2000; Loewen et al., 1998). RpoS has been clearly implicated in expression of the virulenceassociated spv operon of Salmonella (Spector, 1998) and in the acid tolerance that contributes to virulence and

Table 1. Occurrence of osmoregulatory systems in E. coli

The osmoregulatory systems of E. coli K-12 have been described in several reviews (e.g. Booth \& Louis, 1999; Wood, 1999). Evidence regarding the existence of those and other systems in pyelonephritis isolates HU734 and CFT073 has been published (Culham et al., 1994, 1998) and is provided herein. Accumulation of trehalose by E. coli HU734 is very limited due to an RpoS defect (see text and Fig. 3). NT, Not tested.

\begin{tabular}{|c|c|c|c|c|c|}
\hline \multirow[t]{2}{*}{ System } & \multirow[t]{2}{*}{ Function } & \multirow{2}{*}{$\begin{array}{c}\text { Genetic regulators in } \\
\text { E. coli K-12 }\end{array}$} & \multicolumn{3}{|c|}{ System occurrence } \\
\hline & & & $\mathrm{K}-12$ & HU734 & CFT073 \\
\hline $\operatorname{TrkAG}(\mathrm{H}) \mathrm{E}$ & $\mathrm{K}^{+}$uptake & Nil & + & NT & NT \\
\hline $\mathrm{KdpFABC}$ & $\mathrm{K}^{+}$uptake & $\mathrm{KdpDE}$ & + & NT & NT \\
\hline ProP & Osmoprotectant uptake & RpoS, CRP, Fis & + & + & + \\
\hline ProU & Osmoprotectant uptake & $\begin{array}{l}\text { TopA, GyrAB, IHF, HU, } \\
\text { H-NS }\end{array}$ & + & + & + \\
\hline BetTBA & $\begin{array}{l}\text { Choline uptake and } \\
\text { oxidation }\end{array}$ & BetI, ArcA & + & + & + \\
\hline OtsBA & Trehalose synthesis & RpoS & + & \pm & + \\
\hline BetU & Betaine uptake & Unknown & - & + & - \\
\hline $\mathrm{MscL}$ & Solute efflux & Unknown & + & NT & NT \\
\hline $\mathrm{MscS}$ & Solute efflux & Unknown & + & NT & NT \\
\hline
\end{tabular}


transmission for enterohaemorrhagic E. coli (Price et al., 2000; Waterman \& Small, 1996). The relationship between RpoS and virulence is less clear for neonatal meningitis isolates of E. coli K1 (Wang \& Kim, 2000) and disruption of rpoS enhanced long-term colonization of the murine large intestine by rat faecal E. coli isolate BJ4 (Krogfelt et al., 2000). The rpoS loci of laboratory (Jishage \& Ishihama, 1997) and natural (Waterman \& Small, 1996) E. coli isolates are polymorphic (including rpoS defects). It is not yet clear whether RpoS defects can impair virulence pleiotropically, by limiting expression of multiple stress tolerance genes, or whether RpoS contributes to virulence only for particular bacterial species and loci of infection.

This report addresses the roles of ProP, ProU and RpoS in osmotolerance and virulence for two pyelonephritis isolates of E. coli. Strain HU734, used to establish the murine model for ascending urinary tract infection, is a $\mathrm{lac}^{-}$strain isolated from pyelonephritis isolate GR12 by chemical mutagenesis (Hagberg et al., 1983a, b). Introduction of genetic lesions affecting $\mathrm{P}$ pili to E. coli HU734 (Hagberg et al., 1983b) and E. coli DS17 (Roberts et al., 1994) reduced their virulence as indicated by the murine and primate models, respectively. Although these and other data clearly establish an important role for $\mathrm{P}$ pili as virulence determinants in pyelonephritis, the elimination of $\mathrm{P}$ pili did not reduce the virulence of pyelonephritis isolate CFT073 as determined by the murine model (Mobley et al., 1993). These and other observations suggest that E. coli CFT073 is more virulent than E. coli HU734 (Mobley et al., 1993). E. coli strains HU734 and CFT073 have thus been compared during this study of osmoregulation and urovirulence.

\section{METHODS}

Media and growth measurements. Bacterial culture media included Luria-Bertani (LB) medium (Miller, 1972), MOPS minimal medium (Neidhardt et al., 1974) and human urine. MOPS medium was supplemented, unless otherwise stated, with D-glucose $(0 \cdot 2 \%, \mathrm{w} / \mathrm{v})$ as carbon source, $\mathrm{NH}_{4} \mathrm{Cl}$ $(9.5 \mathrm{mM})$ as nitrogen source, amino acids $\left(50 \mu \mathrm{g} \mathrm{ml}^{-1}\right)$ to meet auxotrophic requirements and thiamine $\mathrm{HCl}\left(1 \mu \mathrm{g} \mathrm{ml}^{-1}\right)$. The collection and preparation of human urine, measurements of bacterial growth in minimal medium and in urine were as described previously (Culham et al., 1998). The osmolalities of culture media and human urine specimens were determined with a vapour pressure osmometer (Wescor). The urea content of urine specimens was determined colorimetrically via the reaction of urea with diacetylmonoxime using BUN acid and colour reagents (Sigma; cat. no. 535-B) (Rahmatullah \& Boyde, 1980). The abilities of organic compounds to provide osmoprotection to E. coli were assessed, as described previously (MacMillan et al., 1999), by measuring bacterial plating efficiencies on $\mathrm{NaCl}$ - and osmoprotectant-supplemented MOPS medium.

Bacteria, plasmids and molecular biological manipulations. The E. coli $\mathrm{K}-12$ derivatives used for this study are listed in Table 2. The genotypes of the clinical E. coli isolates and their derivatives are described below and in Table 4. E. coli BJ4, a faecal isolate from a healthy Wistar rat, is rough:K-: H-. It produces type 1 fimbriae and possesses two unidentified, high molecular mass plasmids (Krogfelt et al., 1993). Strain BJ4
rpoS was isolated by bacteriophage P1-mediated transduction of BJ4 to tetracycline resistance from MC4100 rpoS: :Tn10 (Krogfelt et al., 2000). Strain HU734, a lac derivative of acute pyelonephritis isolate GR12, has the following properties: streptomycin and spectinomycin resistance and cysteine auxotrophy, serotype $\mathrm{O} 75: \mathrm{K} 5$, possession of type 1 and $\mathrm{P}$ pili (the latter encoded by a single pap operon), carriage of ColV plasmid, resistance to killing by human and mouse serum, and failure to produce haemolysin (Hagberg et al., 1983a; Mamelak, 1994). Strain CFT073 was isolated from the blood of a patient with pyelonephritis. It has no antibiotic resistance or auxotrophy, is $\mathrm{O}$ non-typable and non-motile, expresses type $1, \mathrm{~S}$ and $\mathrm{P}$ pili (the latter encoded by two pap operons), produces haemolysin and is cytotoxic for cultured human renal epithelial cells (Mobley et al., 1993). Isolation of strains WG541 [HU734 $\Delta$ (putPA)566] and WG671 [WG541 $\Delta$ (proP)218] was described previously (Culham et al., 1998). Deletion $\Delta($ proP $) 218$ eliminates a DNA fragment that extends from $59 \mathrm{bp}$ upstream to $44 \mathrm{bp}$ downstream of proP.

Molecular biological manipulations were carried out as described by Sambrook et al. (1989), plasmid constructs were transformed into E. coli strain S17-1 ipir (derivatives of vector pCVD442) or strain DH5 $\alpha$ and transformants were selected on ampicillin-supplemented LB medium $\left(100 \mu \mathrm{g} \mathrm{ml}^{-1}\right)$. The DNA sequences of the rpoS loci in strains HU734 and CFT073 were determined as described by Culham \& Wood (2000).

Deletions $\Delta$ (proV-proX)567 and $\Delta(r p o S) 2062$ were created in vector pCVD442 (Donnenberg \& Kaper, 1991) and introduced to the chromosomes of strains WG541, CFT073 and their derivatives by allelic replacement. Deletion $\Delta$ (proV-proX)567 was created as follows. The $5 \cdot 2 \mathrm{~kb}$ EcoRI fragment of pOS59 (Haardt \& Bremer, 1996) was inserted into the EcoRI site of vector pGEM7Z to create plasmid pDC70. The $4.6 \mathrm{~kb}$ $A c c \mathrm{I}-\mathrm{MscI}$ fragment of pDC70 was treated with Klenow fragment of DNA polymerase I and religated to create deletion $\Delta$ (proV-proX)567 in plasmid pDC72. The $1.5 \mathrm{~kb}$ EcoRVSmaI fragment of pDC72 was then ligated into the SmaI site of vector pCVD442 to create plasmid pDC76, which contains $686 \mathrm{bp}$ upstream of proV, plus the first $146 \mathrm{bp}$ of proV and $652 \mathrm{bp}$ downstream of proX.

The in-frame rpoS deletion was created using crossover PCR essentially as described by Link et al. (1997). PCR was used to amplify a $593 \mathrm{bp}$ product (including sequence upstream of rpoS) using primers rpoS-No and rpoS-Ni (Table 3) and a $581 \mathrm{bp}$ product (including sequence downstream of rpoS) using primers rpoS-Ci and rpoS-Co2 (Table 3 ) with chromosomal DNA from E. coli CFT073 as template (PCR conditions essentially as described by Brown \& Wood, 1992). These two products were gel-purified, mixed and PCR-amplified using primers rpoS-No and rpoS-Co2. Since $21 \mathrm{bp}$ complementary sequences were included in primers rpoS-Ni and $\mathrm{rpoS}-\mathrm{Ci}$, this mixture supported amplification of a $1.1 \mathrm{~kb}$ product including an in-frame deletion of $r p o S[\Delta(r p o S) 2062]$ encoding a protein composed of the first 6 aa of RpoS, 7 aa added as a result of the 21 bp complementary region and the last 11 aa of RpoS. The $1 \cdot 1 \mathrm{~kb}$ product was digested with $S s t \mathrm{I}$, gel-purified and ligated into the $S s t$ I site of vector pCVD442 to create plasmid pDC96.

Allelic replacement was carried out essentially as described by Mobley et al. (1993). Plasmids pDC76 and pDC96, maintained in E. coli S17-1 $\lambda$ pir, were introduced to selected derivatives of E. coli HU734 or CFT073 by conjugation. Donor and recipient strains were cross-streaked onto LB plates. After incubation at $37^{\circ} \mathrm{C}$, bacteria from the centre of the cross-streak were swabbed onto MOPS minimal medium containing ampicillin $\left(100 \mu \mathrm{g} \mathrm{ml}^{-1}\right)$ and colonies arising were purified on the same 
Table 2. E. coli $\mathrm{K}-12$ strains and plasmids

\begin{tabular}{|c|c|c|}
\hline Strain or plasmid & Genotype & Source (reference) \\
\hline \multicolumn{3}{|l|}{ Strains } \\
\hline $\mathrm{CSH} 4$ & $\mathrm{~F}^{-} \operatorname{trp}$ lacZ rpsL thi & Cold Spring Harbor Laboratory \\
\hline DH5 $\alpha$ & $\begin{array}{l}\mathrm{F}^{-} \phi 80 \mathrm{~d} l a c Z \Delta \mathrm{M} 15 \Delta(\text { lacZYA-argF }) \mathrm{U} 169 \text { recA1 endA1 hsdR17 } \\
\left(\mathrm{r}_{\mathrm{k}}^{-} \mathrm{m}_{\mathrm{k}}^{+}\right) \sup 44 \lambda^{-} \text {thi-1 gyrA relA1 }\end{array}$ & Bethesda Research Laboratories \\
\hline GC202 & GC4468 katG::Tn10 & Schellhorn \& Hassan (1988) \\
\hline GC4468 & $\Delta l a c 4169$ rpsL & Schellhorn \& Hassan (1988) \\
\hline K-12 & Wild-type & E. coli Genetic Stock Centre \\
\hline MC4100 & $\mathrm{F}^{-}$araD139 $\Delta(\operatorname{argF}-$ lac $)$ U169 rpsL150 relA1 deoC1 ptsF25 & Casadaban (1976) \\
\hline NC202 & GC4468 katE::lacZ katG:: Tn10 & Schellhorn \& Hassan (1988) \\
\hline NC4468 & GC4468 katE: : lacZ & Schellhorn \& Hassan (1988) \\
\hline RH90 & MC4100 rpoS359:: Tn10 & Lange \& Hengge-Aronis (1991) \\
\hline S17-1 גpir & 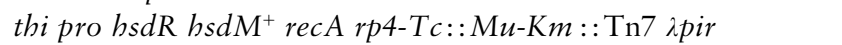 & P. Goodwin (Herrero et al., 1990) \\
\hline \multicolumn{3}{|l|}{ Plasmids } \\
\hline pCVD442 & ori6K mobRP4 $\mathrm{Gm}^{\mathrm{R}} s a c B$ & J. Kaper (Donnenberg \& Kaper, 1991) \\
\hline pOS59 & proU operon in pBR322, $b l a^{+}$ & E. Bremer (Haardt \& Bremer, 1996) \\
\hline pGEM7Z & Cloning vector, $b l a^{+}$ & Promega \\
\hline pDC76 & $\begin{array}{l}\text { A chromosomal DNA fragment including } \Delta \text { (proV-proX)567 } \\
\text { inserted at the SmaI site of pCVD442 (see Methods) }\end{array}$ & This study \\
\hline pDC96 & $\begin{array}{l}\text { A chromosomal DNA fragment including } \Delta(r p o S) 2062 \text { inserted } \\
\text { at the SstI site of pCVD } 442 \text { (see Methods) }\end{array}$ & This study \\
\hline
\end{tabular}

medium. Sucrose selection was carried out as described by Culham et al. (1998). Chromosomal DNA sequences from ampicillin-sensitive colonies were PCR-amplified to identify clones harbouring the desired deletions (see Table 3 for diagnostic primers and PCR products).

Enzyme assays. The GB uptake activities of bacteria cultivated in defined media or human urine were measured as described by Culham et al. (1998), using uniformly labelled ${ }^{14} \mathrm{C}-\mathrm{GB}$ (American Radiolabelled Chemicals) $\left(0 \cdot 2 \mathrm{mM} ; 5 \mu \mathrm{Ci} \mu \mathrm{mol}^{-1}\right)$. Bacteria cultivated in urine $(0.92 \mathrm{~mol} \mathrm{~kg}-1,0.44 \mathrm{M}$ urea) were harvested, washed and resuspended in unsupplemented MOPS medium rendered isotonic by adding $0 \cdot 44 \mathrm{M}$ urea and $0 \cdot 174 \mathrm{M}$ $\mathrm{NaCl}$. The transport assay media also contained $0.44 \mathrm{M}$ urea and were rendered isotonic by adjusting the $\mathrm{NaCl}$ concentration.

The catalase contents of pyelonephritis isolates HU734 and CFT073 and of E. coli K-12 derivatives GC4468 (katE $E^{+}$at $G^{+}$),

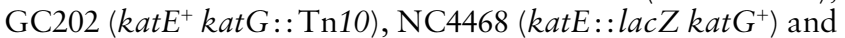
NC202 (katE: : lacZ katG:: Tn10) were determined as follows. Bacteria were grown to stationary phase in $75 \mathrm{ml} \mathrm{LB}$ medium, harvested by centrifugation and resuspended in $7.5 \mathrm{ml} 20 \%$ $(\mathrm{w} / \mathrm{v})$ sucrose. The cell suspensions were sonicated, clarified by centrifugation at 13000 r.p.m. for $3 \mathrm{~min}$ and $20 \mu \mathrm{l}$ of each supernatant was analysed by native gel electrophoresis. Bands with catalase activity were visualized with reagent mixtures, including horseradish peroxidase (Sigma) and hydrogen peroxide, then diaminobenzidine (Sigma) as described by Clare $e t$ al. (1984). The catalase contents of the E. coli K-12 derivatives were as predicted by their genotypes (data not shown).

RpoS detection. RpoS was detected in selected bacterial strains as follows. A few colonies from an overnight culture on LB medium were inoculated into $5 \mathrm{ml}$ fresh liquid LB medium. At a cell density of 30 Klett units, the culture was diluted 40fold by adding $200 \mathrm{ml}$ fresh LB medium and incubated at $37^{\circ} \mathrm{C}$ with shaking to a cell density of 30 Klett units (exponential phase) or 200 Klett units (stationary phase). Cells were collected by centrifugation and resuspended at $4{ }^{\circ} \mathrm{C}$ in $40 \mathrm{mM}$ Tris $/ \mathrm{HCl}(\mathrm{pH} \mathrm{8} \cdot 1)$ containing $25 \%$ sucrose. After treatment with $1 \mathrm{mM}$ EDTA and $0.5 \mathrm{mg}$ lysozyme $\mathrm{ml}^{-1}$ at $0{ }^{\circ} \mathrm{C}$ for $10 \mathrm{~min}$, cells were lysed by adding $0.5 \%$ Brij-58. The Brij lysate was supplemented with $0.01 \mathrm{M} \mathrm{MgCl}_{2}$ and $0 \cdot 2 \mathrm{M}$ $\mathrm{KCl}$, and digested at $37^{\circ} \mathrm{C}$ for $10 \mathrm{~min}$ with $20 \mathrm{mg}$ RNase A $\mathrm{ml}^{-1}$ and $100 \mathrm{mg} \mathrm{DNase} \mathrm{Iml}^{-1}$ in the presence of $1 \mathrm{mM}$ PMSF, followed by sonication for 1 min with a Cosmo Bio Bioruptor. The supernatant after centrifugation for $30 \mathrm{~min}$ at 15000 r.p.m. was used as the cell lysate for the experiments. The protein concentration of cell lysates was determined using the Bio-Rad Protein Assay Kit.

For the measurement of $\sigma$ subunits, a quantitative Western blot analysis was employed using monospecific anti- $\sigma$ antibodies. Anti-RpoS antibodies were raised in rabbits against purified RpoS protein (Jishage \& Ishihama, 1995). In brief, cell lysates were treated with SDS sample buffer $(50 \mathrm{mM}$ Tris $/ \mathrm{HCl}, \mathrm{pH} 6.8,2 \%$ SDS, $1 \%$ 2-mercaptoethanol, $10 \%$ glycerol and $0.025 \%$ bromophenol blue) and separated on SDS polyacrylamide gels $(7.5$ or $10 \%)$. Proteins in the gels were directly electroblotted onto polyvinylidene difluoride membranes (Nippon Genetics). Blots were blocked overnight at $4{ }^{\circ} \mathrm{C}$ in $3 \%$ BSA in PBS, probed with monospecific antibodies against each $\sigma$ subunit, washed with $0.5 \%$ Tween in PBS and incubated with goat anti-rabbit IgG conjugated with hydroperoxidase (Cappel). The blots were developed with 3,3'-diaminobenzidine tetrahydrochloride (Dojindo).

Trehalose assay. Intracellular trehalose levels were determined by NMR spectroscopy as described by MacMillan et al. (1999). Extracts were prepared from cells cultured in MOPS medium supplemented with glycerol as carbon source and $0 \cdot 4 \mathrm{M} \mathrm{NaCl}$ in the absence of organic osmoprotectants.

Colonization of the murine urinary tract. The ability of selected E. coli strains to colonize the murine urinary tract was determined by enumeration of bacteria in the animals' urine, bladders and kidneys 1 and $3 \mathrm{~d}$ after transurethral inoculation 


\section{Table 3. PCR primers and products}

PCR was used during the construction of $\Delta r p o S 2062$ (primers rpoS-No, rpoS-Ni, rpoS-Co2 and rpoS-Ci) to verify chromosomal insertion of $\Delta r p o S 2062$ and $\Delta$ (proV-proX)567 by allelic replacement (primer pairs rpoS1/rpoS2, rpoS-No/rpoS2, proX1/proX2 and proV1/proU4) and to verify the genotypes of bacteria recovered from murine bladders (primer pairs putP1/putP2, proP1/proP2, proV1/proV2 and rpoS8/rpoS2) (see Methods). Primer names designate the genetic loci amplified (the proU operon includes proV, proW and proX; primer proU4 is complementary to a sequence flanking the operon). For primer pairs used as diagnostics during allelic replacement or animal colonization experiments, the last columns list the sizes of the PCR products expected with template DNA from wild-type (WT) bacteria or bacteria harbouring a deletion of the corresponding genetic locus (Deletion). ND, PCR product not detectable under these reaction conditions; NA, primers used only for the construction of $\Delta r p o S 2062$.

\begin{tabular}{|c|c|c|c|}
\hline \multirow[t]{2}{*}{ Primer } & \multirow[t]{2}{*}{ Sequence $\left(5^{\prime}-3^{\prime}\right)$} & \multicolumn{2}{|c|}{ PCR product $(\mathrm{bp})$} \\
\hline & & WT & Deletion \\
\hline $\begin{array}{l}\text { putP1 } \\
\text { putP2 }\end{array}$ & $\begin{array}{l}\text { GGT TGC GTG TGC ATA CCG A } \\
\text { GCC GTT TCG TAG CTC ATG C }\end{array}$ & 202 & 0 \\
\hline $\begin{array}{l}\text { proP1 } \\
\text { proP2 }\end{array}$ & $\begin{array}{l}\text { GCA TTA CTC CGA AGA CCA CG } \\
\text { GGT AGA AGC CAT AAC GCC C }\end{array}$ & 256 & 0 \\
\hline $\begin{array}{l}\text { proV1 } \\
\text { proV2 }\end{array}$ & $\begin{array}{l}\text { GCA TCC ACA GCG AGC GTT CA } \\
\text { GGA GTT CGG CGT CGG ATA T }\end{array}$ & 254 & 0 \\
\hline $\begin{array}{l}\text { proX1 } \\
\text { proX2 }\end{array}$ & $\begin{array}{l}\text { GGG AAC TAC GCA GCG ATG A } \\
\text { GGG AAG CCA TAA TTC GCA CC }\end{array}$ & 206 & 0 \\
\hline $\begin{array}{l}\text { proV1 } \\
\text { proU4 }\end{array}$ & $\begin{array}{l}\text { GCA TCC ACA GCG AGC GTT CA } \\
\text { GAC CAA TGA CAC CAT CGC TG }\end{array}$ & ND & 661 \\
\hline $\begin{array}{l}\text { rpoS1 } \\
\text { rpoS2 }\end{array}$ & $\begin{array}{l}\text { GTT CCG TCA AGG GAT CAC G } \\
\text { GCT TCG ATA TTC AGC CCC TG }\end{array}$ & 1011 & 0 \\
\hline $\begin{array}{l}\text { rpoS8 } \\
\text { rpoS2 }\end{array}$ & $\begin{array}{l}\text { GTA CTG GCA CGT CGA TTC G } \\
\text { GCT TCG ATA TTC AGC CCC TG }\end{array}$ & 161 & 0 \\
\hline $\begin{array}{l}\text { rpoS-No } \\
\text { rpoS2 }\end{array}$ & $\begin{array}{l}\text { CGC GAG CTC ACG TAT TCT GAG TCT TCG GG } \\
\text { GCT TCG ATA TTC AGC CCC TG }\end{array}$ & ND & 613 \\
\hline rpoS-Ni & CCC ATC CAC TAA ACT TAA ACA GAT CCC TTG ACG GAA CAT TC & NA & NA \\
\hline rpoS-Ci & TGT TTA AGT TTA GTG GAT GGG CAG GGG CTG AAT ATC GAA GC & NA & NA \\
\hline rpoS-Co2 & CGC GAG CTC GCT GAT GCC AGT TCC AAA GC & NA & NA \\
\hline
\end{tabular}

with $50 \mu$ l bacterial suspensions (approx. $10^{9}$ bacteria $\mathrm{ml}^{-1}$ ) (Hvidberg et al., 2000). Bladders and kidneys were homogenized on ice for $30 \mathrm{~s}$ using an IKA Laborteknik homogenizer before plating on relevant media. The genotypes of selected isolates from the bladders of infected mice were verified by PCR amplification using the primers listed in Table 3.

\section{RESULTS}

\section{Properties of pyelonephritis isolates HU734 and CFT073: rpos and osmotolerance}

Strain CFT073 is intrinsically more osmotolerant than strain HU734, but similar in osmotolerance to E. coli K12 , as indicated by their rates of growth in glucose- and $\mathrm{NaCl}$-supplemented MOPS minimal medium (Culham et al., 1998 and Fig. 1). For E. coli K-12, these conditions would permit osmoregulation through $\mathrm{K}^{+}$uptake and trehalose synthesis, but not through the uptake of organic osmoprotectants via transporters ProP, ProU and/or BetT (see Table 1).

The relatively slow growth of E. coli HU734 in highosmolality minimal medium suggested that this strain may be deficient in RpoS, the alternative $\sigma$ factor required for osmoregulatory trehalose biosynthesis by E. coli K-12. PCR amplification and DNA sequence analysis revealed that the $r p o S$ gene is present in both HU734 and CFT073 (see Methods). In comparison with E. coli K-12, both harboured a DNA insertion downstream from rpos (Culham \& Wood, 2000) as well as single base changes within rpoS. One single base change would create an amino acid change within RpoS (Q45E). The downstream insertion does not affect the primary sequence of RpoS, however. A further mutation in the rpoS gene of HU734 extended the predicted RpoS protein to include 24 additional C-terminal amino acids.

E. coli HU734 expressed RpoS, as indicated by Western blot analysis, but that protein was lower in electrophoretic mobility than RpoS from E. coli K-12, its derivative CSH4 or E. coli CFT073 (Fig. 2), as expected on the basis of the DNA sequence. The quantity of RpoS detected in both clinical isolates was much higher than that detected in E. coli K-12. Furthermore, RpoS was present at high levels in bacteria from both exponentialand stationary-phase cultures of the clinical isolates, 


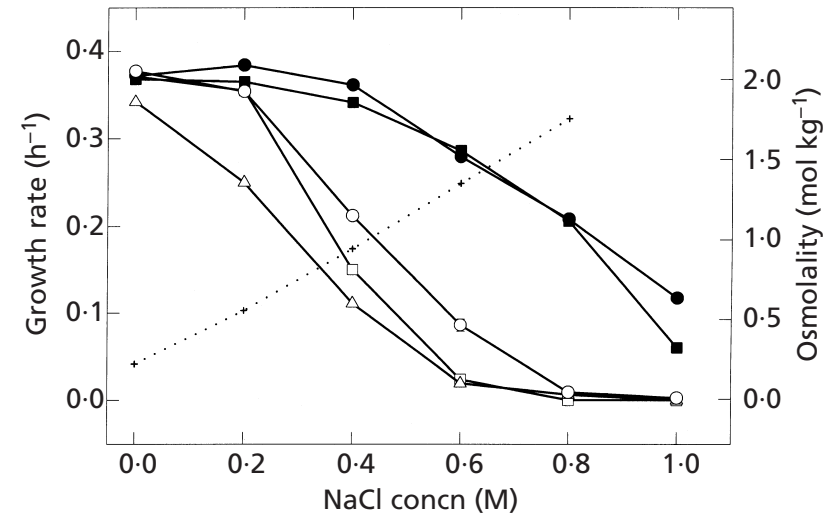

Fig. 1. Osmotolerance of the $E$. coli isolates and their derivatives. The rates of growth of E. coli strains CFT073 $(\bullet, O)$, WG745 (CFT073 rpoS) $(\boldsymbol{\square}, \square)$ and HU734 $(\triangle)$ were measured in $\mathrm{NaCl}$-supplemented MOPS minimal medium in the absence $(O$, $\square, \triangle$ ) or presence $(\mathbf{O}, \boldsymbol{\square})$ of $1 \mathrm{mM} \mathrm{GB}$ (see Methods). Error bars (falling within the symbols) represent the standard deviation of triplicate determinations for strain CFT073 without GB. Other symbols represent single determinations (strain HU734 only) or the means of duplicate determinations. The dotted line represents the osmolalities of the growth media as determined by vapour pressure osmometry.

whereas its expression was growth-phase-dependent in E. coli $\mathrm{K}-12$, as previously observed (Jishage \& Ishihama, 1995). Both pyelonephritis isolates expressed RpoN and neither expressed RpoF under these conditions (data not shown).

The RpoS protein is required for the synthesis of trehalose in stationary-phase E. coli (Hengge-Aronis et al., 1991). E. coli MC4100 (a K-12 derivative) accumulated high levels of trehalose in stationary phase, whereas trehalose was not detected in E. coli RH90 which lacks RpoS (MC4100 rpoS359::Tn10) (Fig. 3). Analysis of cytoplasmic extracts from the pyelonephritis isolates cultivated in high-osmolality minimal medium revealed the accumulation of trehalose to a high level in E. coli CFT073, but to a very low level in E. coli HU734 (Fig. 3), indicating that the RpoS protein present in $E$. coli HU734 is defective in function. MOPS was also present in the extracts from all strains. MOPS accumulates in bacteria cultivated in MOPS medium at high osmolality but it does not serve as an osmoprotectant (MacMillan et al., 1999). No other compound was present at high concentration in the extracts from strains RH90 and HU734, indicating that these strains did not replace trehalose by synthesizing another osmoregulatory solute.

To further assess whether a trehalose biosynthetic lesion or an RpoS defect limited trehalose biosynthesis by $E$. coli HU734, the stationary-phase thermotolerance of strain HU734 was compared with that of strains MC4100 $\left(r p o S^{+}\right)$and RH90 (rpoS359:: Tn10). Using E. coli K-12 derivatives MC4100, RH90 and RO22 (otsA::Tn10 otsB::lac), Hengge-Aronis et al. (1991)

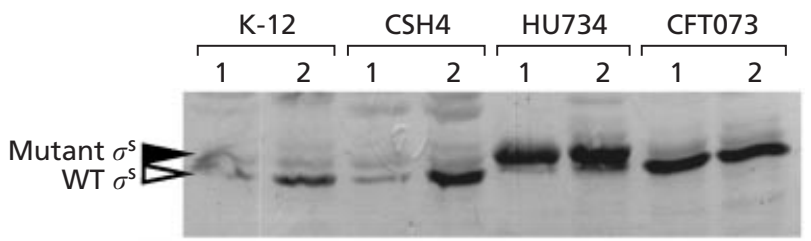

Fig. 2. RpoS contents of $E$. coli isolates. The Western blot displaying the RpoS $\left(\sigma^{S}\right)$ contents of selected strains was prepared as described in Methods. WT, Wild-type. Lanes: 1, bacteria harvested from exponential-phase cultures; 2 , bacteria harvested from stationary-phase cultures.

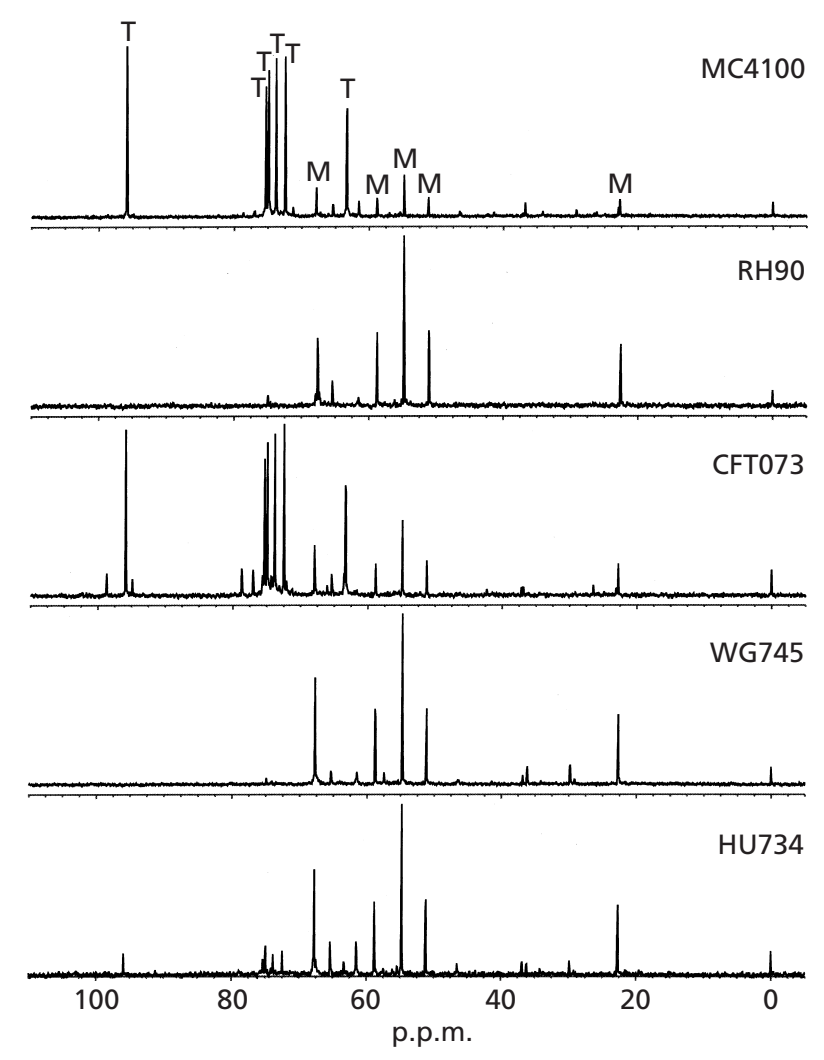

Fig. 3. Trehalose accumulation by $E$. coli isolates. Accumulation of trehalose by selected $E$. coli isolates. Bacteria were cultivated at $37^{\circ} \mathrm{C}$ for $2 \mathrm{~d}$ (strain RH90 only) or overnight in MOPS minimal medium supplemented with glycerol as carbon source and $0.4 \mathrm{M} \mathrm{NaCl}$. Cell extracts were prepared in $\mathrm{D}_{2} \mathrm{O}$ and ${ }^{13} \mathrm{C}$ containing compounds were detected by NMR spectroscopy using (trimethylsylyl)tetradeutero sodium propionate as reference as described by MacMillan et al. (1999). Peak assignments based on the spectra of standard compounds analysed under the same conditions: $\mathrm{T}$, trehalose; $\mathrm{M}$, MOPS. These apply to the corresponding peaks in all spectra. No significant resonances were observed in the region 110-190 p.p.m. (data not shown).

demonstrated that the disruption of rpoS much more dramatically reduced stationary-phase thermotolerance than did disruption of ots $A$ and otsB. The very poor stationary-phase thermotolerance of E. coli HU734 


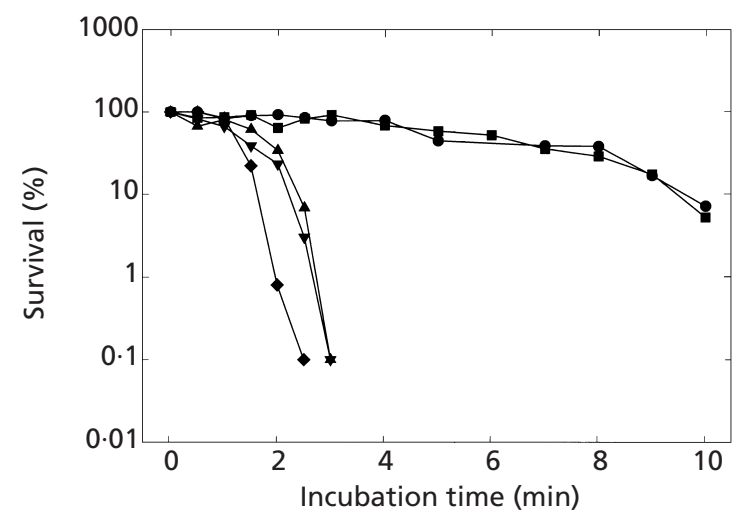

Fig. 4. Stationary-phase thermotolerance of selected $E$. coli strains. The stationary-phase thermotolerance of selected $E$. coli strains was determined as described by Hengge-Aronis et al. (1991) except that the bacteria were cultivated in MOPS minimal medium. Percentage survival is plotted versus period of incubation at $55^{\circ} \mathrm{C}$. $\boldsymbol{\nabla}, \mathrm{HU734} ; 0, \mathrm{MC4100}\left(\mathrm{rpoS}^{+}\right)$; $\boldsymbol{\Delta}, \mathrm{RH} 90$

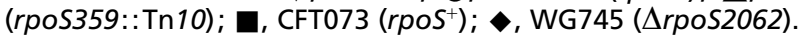

(comparable to that of E. coli RH90) (Fig. 4) suggested that the limited trehalose accumulation in E. coli HU734 (Fig. 3) resulted from an rpoS lesion with pleiotropic effects on thermotolerance. The catalase contents of the pyelonephritis isolates were also assessed in comparison with those of selected E. coli K-12 derivatives (see Methods). Expression of KatE by E. coli K-12 is RpoSdependent, whereas expression of KatG is not (Loewen et al., 1998). Strains HU734 and CFT073 expressed KatG but not KatE (data not shown), so this test did not further indicate the status of RpoS in these bacteria.

Recently, Ohnuma et al. (2000) showed that the Cterminal 16 aa region of RpoS plays an important role for in vitro transcription in potassium-glutamatesupplemented media and for the expression of promoter-lac $Z$ fusion constructs in vivo. It is possible that the C-terminal extension encoded by the rpoS allele in E. coli HU734 interferes with these critical functions.

\section{Impact of rpos, proP and proU lesions on osmoregulatory solute accumulation and osmotolerance for $E$. coli strains HU734 and CFT073}

The rpoS locus was deleted from E. coli CFT073 (see Methods). The in-frame $r p o S$ deletion in strain WG745 [CFT073 $\Delta$ (rpoS)2062] eliminated trehalose accumulation (Fig. 3) and rendered the stationary-phase thermotolerance of strain WG745 similar to that of E. coli RH90 (rpoS:: Tn10) (Fig. 4), as expected. No compound other than MOPS replaced trehalose in E. coli WG745 (Fig. 3). The rpoS defect rendered the growth rate of CFT073 in very high-osmolality, NaCl-supplemented minimal medium $\left(1 \cdot 4 \mathrm{~mol} \mathrm{~kg}^{-1}\right)$ comparable to that of HU734, but this defect did not account for their different abilities to tolerate lower osmolalities (e.g. $0 \cdot 4 \mathrm{~mol} \mathrm{~kg}^{-1}$ ) (Fig. 1).

The osmotolerance of both pyelonephritis isolates was enhanced by osmoprotectant GB (1 mM) (Culham et al.,

Table 4. GB uptake activities of bacteria cultivated in minimal salts medium or human urine

The E. coli strains were derived from pyelonephritis isolates HU734 (Hagberg et al., 1983a; Culham et al., 1998) and CFT073 (Mobley et al., 1993) (see Methods). The $r p o S^{-}$designation is applied to E. coli HU734 to emphasize its difference from the wild-type alleles of strains K-12 and CFT073. It is possible that E. coli HU734 and its parent, GR12, share the same rpoS allele, however. Bacteria were cultivated to late exponential phase in the following media: MOPS media (glycerol as carbon source) that were not $(\mathrm{MOPS}-\mathrm{NaCl}$ ) or were (MOPS $+\mathrm{NaCl})$ supplemented with $0 \cdot 4 \mathrm{M} \mathrm{NaCl}\left(0 \cdot 25\right.$ and $0.95 \mathrm{~mol} \mathrm{~kg}^{-1}$ respectively); human urine with an osmolality of $0.92 \mathrm{~mol} \mathrm{~kg}^{-1}$ and a urea concentration of $0.44 \mathrm{M}$; MOPS medium supplemented with $0 \cdot 44 \mathrm{M}$ urea and $0 \cdot 13 \mathrm{M} \mathrm{NaCl}$ $\left(0 \cdot 92 \mathrm{~mol} \mathrm{~kg}^{-1}\right)$ (MOPS $+\mathrm{NaCl}+$ urea) ; MOPS medium supplemented with $0 \cdot 44 \mathrm{M}$ urea, $0 \cdot 13 \mathrm{M} \mathrm{NaCl}\left(0 \cdot 92 \mathrm{~mol} \mathrm{~kg}{ }^{-1}\right)$ and $0 \cdot 1 \mathrm{mM} \mathrm{GB}$ $(\mathrm{MOPS}+\mathrm{NaCl}+$ urea $+\mathrm{GB})$. Initial rates of GB uptake, measured as described in Methods, are means of triplicate determinations $( \pm \mathrm{SEM})$ representative of at least two replicate experiments. NT, Not tested.

\begin{tabular}{|c|c|c|c|c|c|c|c|c|c|}
\hline \multicolumn{5}{|l|}{ Strain } & \multicolumn{5}{|c|}{ Betaine uptake activity $\left[\mathrm{nmol} \mathrm{min}^{-1}(\mathrm{mg} \text { protein })^{-1}\right]$} \\
\hline \multirow[t]{2}{*}{ Name } & \multirow[t]{2}{*}{ Parent } & \multicolumn{3}{|c|}{ Relevant genotype } & \multirow{2}{*}{$\begin{array}{l}\text { MOPS }-\mathrm{NaCl} \\
\left(0 \cdot 25 \mathrm{~mol} \mathrm{~kg}^{-1}\right)\end{array}$} & \multirow{2}{*}{$\begin{array}{c}\text { MOPS }+0.4 \mathrm{M} \\
\mathrm{NaCl} \\
\left(0.95 \mathrm{~mol} \mathrm{~kg}^{-1}\right)\end{array}$} & \multirow{2}{*}{$\begin{array}{l}\text { Human urine } \\
\left(0.92 \mathrm{~mol} \mathrm{~kg}^{-1}\right)\end{array}$} & \multirow{2}{*}{$\begin{array}{c}\text { MOPS }+0.13 \mathrm{M} \\
\mathrm{NaCl}+\text { urea } \\
\left(0.92 \mathrm{~mol} \mathrm{~kg}^{-1}\right)\end{array}$} & \multirow{2}{*}{$\begin{array}{c}\text { MOPS + 0.13 M } \\
\mathrm{NaCl}+\text { urea }+\mathrm{GB} \\
\left(0.92 \mathrm{~mol} \mathrm{~kg}^{-1}\right)\end{array}$} \\
\hline & & rpos & proP & proU & & & & & \\
\hline HU734 & - & - & + & + & NT & NT & $18 \pm 1$ & $50 \pm 2$ & $16 \pm 0 \cdot 3$ \\
\hline WG541 & HU734 & - & + & + & $10 \pm 2$ & $192 \pm 7$ & $20 \pm 3$ & $54 \pm 1$ & NT \\
\hline WG671 & HU734 & - & - & + & $1 \pm 1$ & $115 \pm 4$ & $5 \pm 1$ & $50 \pm 1$ & NT \\
\hline WG694 & HU734 & - & + & - & $8 \pm 1$ & $104 \pm 4$ & $25 \pm 1$ & $39 \pm 1$ & NT \\
\hline WG695 & HU734 & - & - & - & $3 \pm 1$ & $37 \pm 1$ & $3 \pm 1$ & $15 \pm 1$ & NT \\
\hline CFT073 & - & + & + & + & $9 \pm 1$ & $55 \pm 1$ & $7 \pm 1$ & $26 \pm 1$ & $10 \pm 1$ \\
\hline WG672 & CFT073 & + & - & + & $1 \pm 4$ & $43 \pm 8$ & $2 \pm 1$ & $18 \pm 1$ & NT \\
\hline WG697 & CFT073 & + & + & - & $3 \pm 3$ & $18 \pm 1$ & $10 \pm 1$ & $11 \pm 0 \cdot 2$ & NT \\
\hline WG696 & CFT073 & + & - & - & $5 \pm 2$ & $1 \pm 1$ & $0 \cdot 02 \pm 0 \cdot 20$ & $0 \cdot 1 \pm 0 \cdot 1$ & NT \\
\hline WG745 & CFT073 & - & + & + & $1 \pm 1$ & $54 \pm 3$ & $8 \pm 0 \cdot 3$ & NT & NT \\
\hline WG746 & CFT073 & - & - & - & $0 \cdot 1 \pm 0 \cdot 2$ & $0 \cdot 01 \pm 0 \cdot 01$ & $1 \pm 1$ & NT & NT \\
\hline
\end{tabular}


1998 and Fig. 1). This was anticipated on the basis of earlier evidence that each possessed genetic loci proP and proU (Culham et al., 1994 and unpublished data). Loci proP and proU were deleted from each strain, both singly and together, in an effort to assess whether ProP and ProU were the only contributors to osmoprotection for the clinical isolates and whether those systems contributed to virulence (see Methods). Initial rates of GB uptake were measured for bacteria cultivated in MOPS minimal medium supplemented with or without $0.4 \mathrm{M} \mathrm{NaCl}$, the concentration at which the largest stimulation of bacterial growth by GB had been observed for E. coli HU734 (Culham et al., 1998). The osmolalities of these media were 1.0 and $0.2 \mathrm{~mol} \mathrm{~kg}^{-1}$, respectively. As for E. coli K-12 (Wood, 1999), GB uptake activity was dramatically elevated when osmotic stress was imposed (Table 4).

The GB uptake activities attained in strain CFT073 were similar to those observed with E. coli K-12 (Grothe et al., 1986). For these late-exponential-phase bacteria, deletion of $r p o S$ reduced the GB uptake activity attained in the absence of osmotic stress but not in its presence (Table 4, compare strains CFT073 and WG745). All the GB uptake could be attributed to transporters ProP and ProU, since strain WG696 $[\Delta($ proP $) 218$ $\Delta$ (proV-proX)567] was devoid of activity. The GB uptake activities observed in strain HU734 were threeto fourfold higher than those of CFT073 and residual GB uptake activity was observed after transporters ProP and ProU were eliminated (Table 4, see strain WG695). Analysis of the initial rate of GB uptake as a function of GB concentration for strain WG695 [HU734 $\Delta($ putPA)101 $\Delta$ (proP)218 $\Delta$ (proV-proX)567] yielded a $K_{\mathrm{m}}$ for the residual activity of $22 \mu \mathrm{M}$. The GB concentrations at which betaine uptake rates were measured included $7 \cdot 3,17 \cdot 3,27 \cdot 3,57 \cdot 3,87 \cdot 3$ and $147 \cdot 3 \mu \mathrm{M}$. This $K_{\mathrm{m}}$ value clearly distinguished $\mathrm{Bet} \mathrm{U}$ from transporters ProP $\left[K_{m}(\mathrm{~GB}) 100 \mu \mathrm{M}\right]$ and ProU $\left[K_{\mathrm{m}}(\mathrm{GB}) 1 \mu \mathrm{M}\right]$. The newly identified transporter, designated BetU, was capable of mediating osmoprotection by GB or proline betaine but not proline as indicated by an osmoprotection assay (see Methods), again distinguishing it from systems ProP and ProU. This transporter is not present or not expressed in E. coli K-12 and E. coli CFT073.

\section{Contribution of osmoprotectant uptake to bacterial growth in human urine}

To assess their responses to growth in human urine, the GB uptake activities of the pyelonephritis isolates were examined after cultivation in high-osmolality human urine and various iso-osmolal minimal salts media. Human urine contains both GB $(78 \pm 65 \mu \mathrm{M}$ in normal humans) and proline betaine $(298 \pm 687 \mu \mathrm{M}$ in normal humans) (Lever et al., 1994a, b). The urea content of the urine used for these experiments was $0.44 \mathrm{M}$ (see Methods).

The GB uptake activities of bacteria cultivated in this urine were more similar to those of bacteria cultivated in

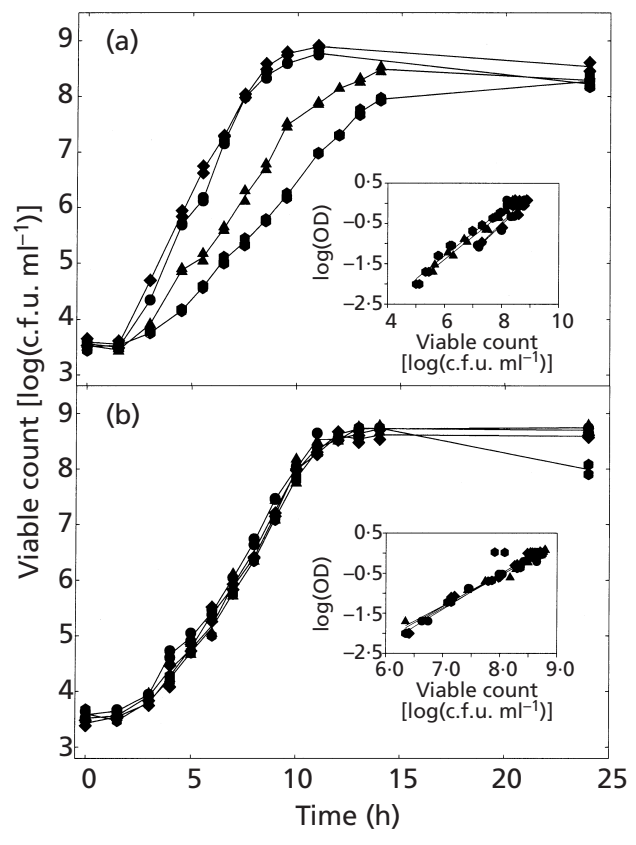

Fig. 5. Growth of selected $E$. coli isolates and their derivatives in high-osmolality human urine. Urine was prepared and bacterial growth was monitored as described in Methods. (a) The growth of $E$. coli strains WG541 (proP $P^{+}$proU $\left.^{+}, 0\right)$, WG671 (pro $P^{-}$proU $\left.^{+}, \mathbf{A}\right)$, WG694 (proP $P^{+}$proU $\left.^{-}, \diamond\right)$ and WG695 (proPproU ${ }^{-}$, ) in human urine with a pH of 5.6 and an osmolality of $0.86 \mathrm{~mol} \mathrm{~kg}^{-1}$ was determined by dilution plating and measurement of $\mathrm{OD}_{600}$ as described in Methods. (b) Growth of E. coli strains CFT073 (proP $P^{+}$proU $^{+}$rpoS $\left.^{+}, 0\right)$ ), WG696 (proP $P^{-}$ proU $\left.{ }^{-} \operatorname{rpoS}^{+}, \mathbf{\Delta}\right), \mathrm{WG745}\left(\right.$ proP $^{+}$proU $^{+}$rpoS $\left.^{-}, \diamond\right)$ and WG746 (proP $P^{-}$proU $^{-}$rpos $^{-},-$) in human urine with a pH of 5.6 and an osmolality of $1.0 \mathrm{~mol} \mathrm{~kg}^{-1}$ was determined by dilution plating and measurement of $\mathrm{OD}_{600}$ as described in Methods. Insets show relationships between viable count and $\mathrm{OD}_{600}$.

MOPS medium of similar osmolality and urea content (compare data columns 3 and 4 of Table 4 ) than to those of bacteria cultivated in iso-osmolal urea-free MOPS medium (compare data columns 3 and 2 of Table 4). The activities of bacteria cultivated in urine were most similar to those of bacteria grown in GB-supplemented MOPS medium of similar osmolality and urea content (compare data columns 3 and 5 of Table 4). Thus the factors controlling expression and activity of the osmoregulatory GB transporters in the pyelonephritis isolates during growth in human urine were consistent with those identified during studies of E. coli K-12 (see Discussion). Osmolality due to solutes other than urea was the primary modulator of GB uptake activity. Although all three GB transporters (ProP, ProU and BetU) were active in urine-grown bacteria, most activity could be attributed to ProP (Table 4).

Betaine uptake via transporters ProP and ProU was expected to stimulate the growth of E. coli and deletion of the transporter genes was expected to impair it in high-osmolality human urine (Chambers \& Lever, 1996). Elimination of transporters ProP and ProU impaired but did not eliminate the growth of E. coli HU734 in human urine $\left(0.86 \mathrm{~mol} \mathrm{~kg}^{-1}\right.$; Fig. 5a). Elim- 
Table 5. Experimental colonization of the murine urinary tract

Colonization of the murine urinary tract was determined 1 and $3 \mathrm{~d}$ after transurethral inoculation with bacterial cell suspensions $\left(10^{8}-10^{9}\right.$ c.f.u. $\left.\mathrm{ml}^{-1}\right)$ (see Methods). $n$, Number of tissues analysed; FI, fraction of tissues infected; Mean, $\log$ [geometric mean c.f.u. $(\mathrm{ml} \text { urine })^{-1}$ ] or $\log [$ geometric mean c.f.u. per tissue (bladder and kidneys)]; A, mean greater than the corresponding value for strain BJ4 with $P \leqslant 0 \cdot 01 ; B$, mean greater than the corresponding value for strain HU734 with $P \leqslant 0 \cdot 01$ (determined with the Mann-Whitney test); NSD, not significantly different.

\begin{tabular}{|c|c|c|c|c|c|c|c|c|}
\hline \multirow{2}{*}{$\begin{array}{l}\text { E. coli } \\
\text { strain }\end{array}$} & \multirow[t]{2}{*}{ Sample } & \multicolumn{3}{|c|}{ Day 1} & \multicolumn{3}{|c|}{ Day 3} & \multirow{2}{*}{$\begin{array}{c}P \text { for day } 1 \rightarrow \\
3 \text { decrease }\end{array}$} \\
\hline & & $n$ & FI & Mean & $n$ & FI & Mean & \\
\hline CFT073 & Urine & 12 & $1 \cdot 00$ & $6 \cdot 2^{\mathrm{A}}$ & 10 & $0 \cdot 60$ & $2 \cdot 7$ & $\leqslant 0 \cdot 01$ \\
\hline HU734 & Urine & 9 & $1 \cdot 00$ & $6 \cdot 0^{\mathrm{A}}$ & 11 & $0 \cdot 50$ & $2 \cdot 1$ & $\leqslant 0 \cdot 01$ \\
\hline BJ4 & Urine & 6 & $0 \cdot 50$ & $1 \cdot 3$ & 6 & $0 \cdot 50$ & $1 \cdot 4$ & NSD \\
\hline CFT073 & Bladder & 12 & $1 \cdot 00$ & $5 \cdot 3^{\mathrm{A}}$ & 11 & $1 \cdot 00$ & $4 \cdot 2^{\mathrm{A}, \mathrm{B}}$ & $\leqslant 0 \cdot 05$ \\
\hline HU734 & Bladder & 11 & $1 \cdot 00$ & $4 \cdot 9^{\mathrm{A}}$ & 12 & $1 \cdot 00$ & $3 \cdot 3^{\mathrm{A}}$ & $\leqslant 0 \cdot 01$ \\
\hline BJ4 & Bladder & 6 & $1 \cdot 00$ & $3 \cdot 2$ & 6 & $1 \cdot 00$ & $2 \cdot 3$ & NSD \\
\hline CFT073 & Kidneys & 12 & $0 \cdot 42$ & $1 \cdot 7$ & 12 & $0 \cdot 42$ & $1 \cdot 6$ & NSD \\
\hline HU734 & Kidneys & 6 & $0 \cdot 33$ & $1 \cdot 9$ & 6 & $0 \cdot 33$ & $1 \cdot 0$ & NSD \\
\hline BJ4 & Kidneys & 6 & $0 \cdot 33$ & $1 \cdot 4$ & 6 & $0 \cdot 33$ & $1 \cdot 2$ & NSD \\
\hline
\end{tabular}

ination of system ProU had no effect unless ProP was also absent. This was consistent with the larger contribution from ProP than from ProU to GB uptake by the urine-grown bacteria (Table 4). As observed previously (Culham et al., 1998), the relationship between the $\log$ (bacterial c.f.u. $\mathrm{ml}^{-1}$ ) and $\log$ (optical density) differed for bacteria retaining and lacking transporter ProP (inset, Fig. 5a). The higher absorbance per unit concentration for bacteria lacking ProP probably resulted from their lower hydration and higher refractive index, although differences in cell size and/or shape could also alter this relationship. The activities of transporters ProU and BetU neither counteracted this effect nor stimulated bacterial growth to the level attained in the presence of ProP. Nevertheless, the growth rate of strain WG695 (AproP $\Delta$ proU) in urine (measured as $0.29 \mathrm{~h}^{-1}$ ) was much higher than that of strain HU734 $\left(\right.$ proP $^{+}$proU ${ }^{+}$) in urea-free minimal medium of comparable osmolality, without or with GB (approx. 0.15 and $0.24 \mathrm{~h}^{-1}$, respectively; Fig. 1 and Culham et al., 1998). System BetU may have contributed to this unexpectedly rapid growth.

Elimination of ProP, ProU or both transporters had no effect on the growth of E. coli CFT073 in high-osmolality human urine $\left(0.86 \mathrm{~mol} \mathrm{~kg}{ }^{-1}\right.$; data not shown). The growth rate attained by strain WG696 (sproP $\Delta$ proU) in $0.86 \mathrm{~mol} \mathrm{~kg}^{-1}$ urine $\left(0.45 \mathrm{~h}^{-1}\right)$ was again much higher than that attained by the transporter-proficient parent strain in urea-free MOPS medium of comparable osmolality, without or with GB (approx. 0.24 and 0.37 $\mathrm{h}^{-1}$, respectively; see Fig. 1). Furthermore, neither deletion of proP and proU nor deletion of $r p o S$ impaired the growth of E. coli CFT073 in human urine with an even higher osmolality $\left(0.99 \mathrm{~mol} \mathrm{~kg}^{-1}\right.$, Fig. 5b). This very rapid growth was particularly surprising since bacteria lacking both transporters were devoid of GB uptake activity (see Table 4) and those lacking RpoS were unable to synthesize trehalose (Fig. 3). In contrast to the behaviour observed for E. coli HU734 and its derivatives (inset to Fig. 5a), the relationship between the $\log$ (optical density) and $\log$ (bacterial c.f.u. $\mathrm{ml}^{-1}$ ) was essentially the same for CFT073 and the derivatives examined here (inset, Fig. 5b). These observations suggest that a mechanism not active in strain HU734 contributes to the hydration and rapid growth of E. coli CFT073 in high-osmolality human urine.

\section{Contributions of RpoS and osmoprotectant uptake to bacterial colonization of the murine urinary tract}

The virulence of the two pyelonephritis isolates and their derivatives was assessed with the murine model of ascending urinary tract infection using rat faecal isolate E. coli BJ4 (Krogfelt et al., 2000) as a control. For these experiments, mice were inoculated transurethrally with a dense bacterial suspension (approx. $10^{9} \mathrm{ml}^{-1}$ ), obviating requirements for ascent of the urethra and proliferation within the urethra and bladder. All three strains persisted in the murine urinary tract postinoculation (Table 5, Fig. 6). The numbers of bacteria recovered from day 1 urine samples and day 1 and 3 bladder homogenates of animals inoculated with the pyelonephritis isolates were significantly higher than those recovered after inoculation with faecal isolate BJ4 (numbers labelled ' $A$ ' in Table 5). Colonization of the urinary tract by strains CFT073 and HU734 was similar despite their differences in osmotolerance. Significant decreases in numbers of bacteria recovered from urine and bladder homogenates, but not from kidney homogenates, were observed from day 1 to day 3 for the pyelonephritis isolates. The numbers of bacteria recovered from the kidneys were low and did not vary significantly among the infecting strains. Deletion of proP, proU and/or rpos had little impact on 


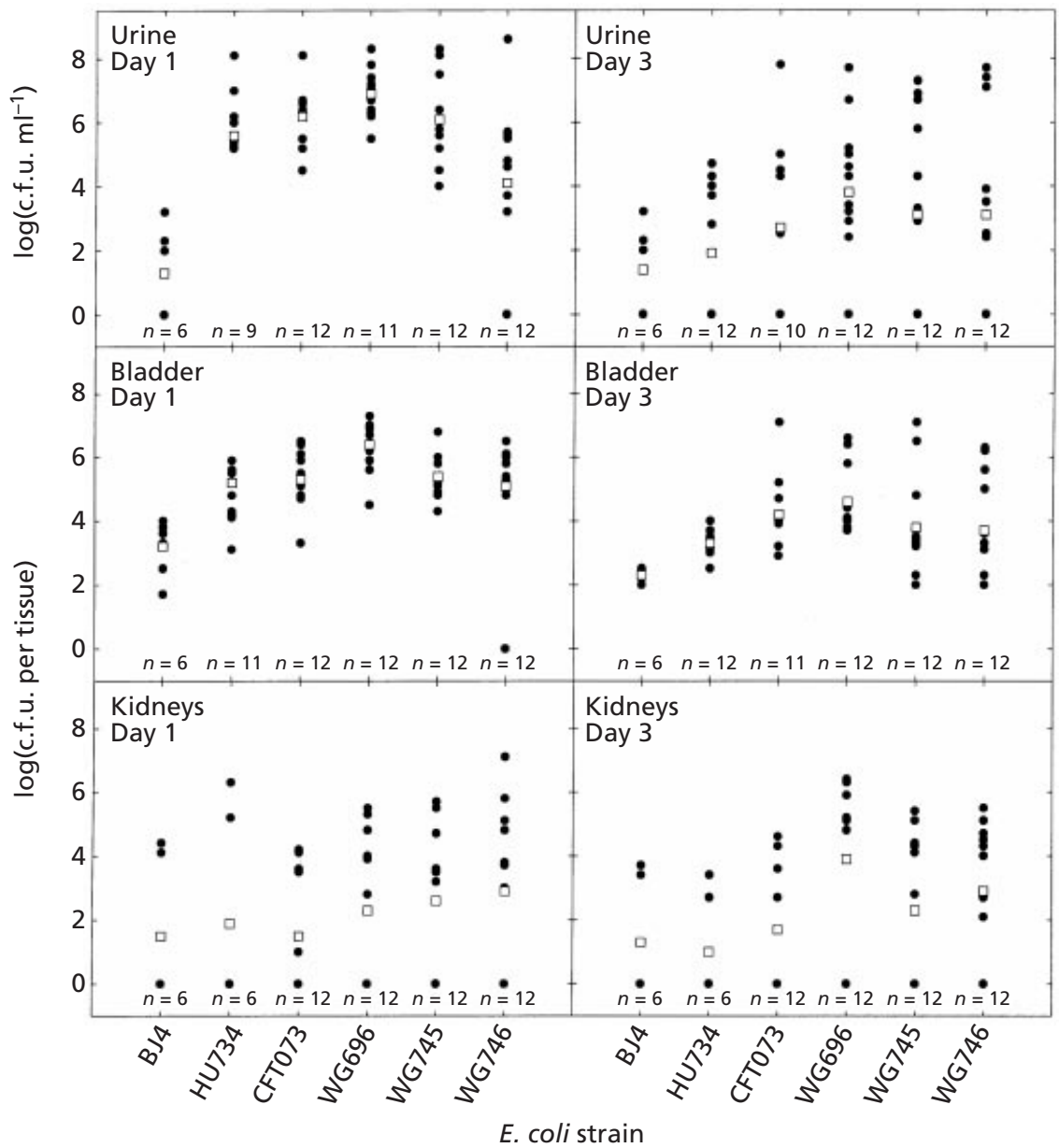

Fig. 6. Colonization of the murine urinary tract by E. coli strains CFT073, HU734, BJ4 and derivatives. Colonization of the murine urinary tract was determined 1 and $3 \mathrm{~d}$ after transurethral inoculation with bacterial cell suspensions (approx. $10^{9}$ c.f.u. $\mathrm{ml}^{-1}$ ) (see Methods). represents log(c.f.u. $\mathrm{ml}^{-1}$ ) or log(c.f.u. per tissue) for individual animals, with a value of 1 c.f.u. assigned to cases in which no bacteria were recovered. represents log(geometric mean c.f.u. $\mathrm{ml}^{-1}$ ) or log(geometric mean c.f.u. per tissue). $n$, Number of tissues analysed. The $E$. coli strains were BJ4 (wild-type), HU734 (GR12 lac ${ }^{-}$), CFT073 (wild-type), WG696 (CFT073 proP $P^{-}$proU $^{-}$), WG745 (CFT073 rpos $^{-}$) and WG746 (WG696 rpos ${ }^{-}$). colonization of the murine urinary tract for the pyelonephritis isolates (Fig. 6 and data not shown). Lesion rpoS: : Tn10 was also without effect on urinary tract colonization by faecal isolate BJ4 (data not shown).

\section{DISCUSSION}

Unlike other inhabitants of the large intestine, UPEC can ascend the urinary tract and persist there despite effective host defences. Virulence factors currently associated with UPEC include adhesive organelles (particularly type 1 and $\mathrm{P}$ pili), toxins (haemolysin, cytotoxic necrotizing factor), iron-acquisition systems (e.g. aerobactin), LPS and capsular material (Donnenberg \& Welch, 1996; Mulvey et al., 2000). Recent evidence differentiates the roles of type 1 and $\mathrm{P}$ pili as determinants of bladder and kidney colonization, respectively, and indicates that UPEC can invade and persist within bladder tissue (Donnenberg \& Welch, 1996; Mulvey et al., 2000). It also illustrates the complex interplay between pathogen and host during ascent of the urinary tract, ultimately resulting in transient, recurrent or persistent infection. Although genomic sequence-based approaches are clarifying the evolutionary origins and epidemiology of virulence for uropathogenic and other clinical E. coli strains (Guyer et al.,
1998; Reid et al., 2000), there is a continuing need to identify determinants of virulence for uropathogenic bacteria.

As it ascends the urinary tract and invades host tissues, E. coli must adapt to stresses imposed by that environment. The high osmolality, high urea concentration, low $\mathrm{pH}$ and organic acid content of urine are widely believed to challenge the growth and survival of E. coli within mammalian urinary tracts (Donnenberg \& Welch, 1996; Kunin, 2000; Mulvey et al., 2000). Urea is a major contributor to urinary osmolality but, unlike other urinary osmolytes, it readily crosses the cytoplasmic membrane of E. coli (Zeidel et al., 1992; K. I. Racher \& J. M. Wood, unpublished data). Data reported here support the view that urea and other urinary osmolytes impose different stresses on E. coli (Randall et al., 1996). The GB uptake activity of bacteria cultivated in urine with an osmolality of $0.92 \mathrm{~mol} \mathrm{~kg}^{-1}$ and a urea content of $0.44 \mathrm{M}$ was much lower than that of bacteria cultivated in iso-osmolal $\mathrm{NaCl}$ supplemented MOPS medium, more similar to that of bacteria cultivated in iso-osmolal $\mathrm{NaCl}$ - and ureasupplemented MOPS medium, and very similar to that of bacteria cultivated in iso-osmolal $\mathrm{NaCl}-$, urea- and GB-supplemented MOPS medium (Table 4). Only 
cytoplasmic-membrane-impermeant osmolytes induce transcription of the genes encoding ProP and ProU and activate the transporters themselves (Wood, 1999). Growth in the presence of GB attenuates the osmotically induced transcription of both proP and proU, perhaps because GB uptake attenuates the signal to which these systems respond (Cairney et al., 1985; Sutherland et al., 1986). Thus the GB uptake activity of the pyelonephritis isolates correlates with the medium osmolality due to membrane-impermeant osmolytes and the availability of GB as an osmoprotectant during growth, phenomena consistent with the behaviour of E. coli K-12 (Wood, 1999). Despite the failure of urea to stimulate GB uptake, betaine accumulation invoked by osmotic stress can attenuate the growth-inhibitory effects of urea (Randall et al., 1996). Thus, osmotic-stress-induced betaine accumulation may be significant as an antidote to urea toxicity for urinary tract bacteria.

The urinary osmolality contributed by solutes other than urea is not particularly high, even for unusually concentrated urine. For $0.9 \mathrm{~mol} \mathrm{~kg} \mathrm{~kg}^{-1}$ urine, contributed by volunteers after $14 \mathrm{~h}$ food and water deprivation, it is comparable to that of MOPS minimal medium supplemented with only approximately $0.13 \mathrm{M} \mathrm{NaCl}$. In the absence of urea, addition of $0 \cdot 13 \mathrm{M} \mathrm{NaCl}$ to MOPS medium does not inhibit the growth of E. coli CFT073 but it does reduce the growth rate of E. coli HU734 (Fig. 1). The slower growth of HU734 is not likely due to the impact of its rpoS defect on trehalose accumulation, since an rpoS deletion had no effect on the growth of strain CFT073 under these conditions (Fig. 1, strains CFT073 and WG745). Among the other osmoregulatory systems known through studies of E. coli K-12 (Table 1), only $\mathrm{K}^{+}$transporter Trk would be expected to contribute to osmotolerance under these conditions (no organic osmoprotectant, $\mathrm{K}^{+}$at approximately $75 \mathrm{mM}$ ). Further experimentation will determine whether E. coli HU734 is deficient in Trk and whether such a difference can account for its limited ability to tolerate low salinities.

Urine contains betaines and transporters ProP and ProU mediate betaine-based osmoprotection for E. coli K-12. It was therefore suggested that ProP and/or ProU may contribute to the virulence of UPEC (Chambers \& Lever, 1996; Culham et al., 1994, 1998). ProP and ProU are widespread among $E$. coli isolates (Culham et al., 1994) and they do contribute to GB uptake and osmotolerance for pyelonephritis isolates HU734 and CFT073 (Fig. 1 and Tables 4 and 5) (Culham et al., 1998). However, deletion of proP and proU did not eliminate osmoprotection by betaine and it only partly attenuated growth in high-osmolality human urine for E. coli HU734 (Fig. 5a). Deletion of proP and proU eliminated osmoprotection but did not attenuate growth in high-osmolality urine for E. coli CFT073 (Fig. 5b). We therefore sought evidence that other osmoregulatory mechanisms contribute to the growth of these bacteria in human urine.

The failure of proP and proU defects to attenuate the growth of strain CFT073 in high-osmolality human urine did not result from trehalose accumulation since a further rpoS deletion also failed to attenuate growth under those conditions [compare strains WG696 ( $\Delta$ proP $\Delta$ proU $r p o S^{+}$) and WG746 ( $\Delta$ proP $\Delta$ proU $\Delta r p o S$ ), Fig. 5b]. Strain HU734 is less osmotolerant than strain CFT073 in the absence of organic osmoprotectants (Fig. 1) but it harbours a betaine transporter, BetU, which is not detected in strains K-12 or CFT073 (Table 4). Like ProP and ProU, BetU is likely to ameliorate the effects of high osmolality and urea content on the growth of $E$. coli HU734 in urine. The genetic locus encoding BetU will now be identified and effects of its deletion on growth of E. coli HU734 in urine determined.

In addition to ProP and ProU, system BetTIBA mediates choline uptake and oxidation, leading to osmoprotection of E. coli $\mathrm{K}-12$ by GB (Table 1 ). BetTIBA is functional in strains HU734 and CFT073 as indicated by PCR-based detection of the bet T locus and osmoprotection by choline (D. E. Culham \& J. M. Wood, unpublished data). Choline is present in human urine at levels (approx. $30 \mu \mathrm{M}$ ) (Altman, 1961) above the $K_{\mathrm{m}}$ of BetT $(8 \mu \mathrm{M})$ (Styrvold et al., 1986), but $\mathrm{O}_{2}$, required for the oxidation of choline to GB by BetBA, may be limiting in the urinary tract environment. Since choline can serve as an osmoprotectant in vitro for both HU734 and CFT073, it is unlikely that the different effects of proP and proU deletions on growth of strains HU734 and CFT073 in urine reflect the compensatory activity of system BetTIBA. Nevertheless, the possibility that this system contributes to growth of the pyelonephritis isolates in high-osmolality urine must be considered. To determine whether a urinary constituent other than GB provides osmoprotection and/or urea protection to $E$. coli CFT073 and its derivatives, we tested that strain for osmoprotection by diverse organic compounds (D. E. Culham, A. Lu \& J. M. Wood, unpublished data). Only choline was growth-stimulatory.

Taken together, these results suggest that E. coli strains K-12 and CFT073 possess an osmoregulatory mechanism distinct from trehalose or betaine accumulation, not shared by E. coli HU734, that confers osmotolerance at the low-salinity characteristic of human urine (perhaps a $\mathrm{K}^{+}$accumulation mechanism). In contrast, only strain HU734 contains organic osmoprotectant transporter BetU. Past research has revealed broad variations in osmotolerance among naturally occurring E. coli isolates (Kunin et al., 1992). Perhaps the differences between pyelonephritis isolates HU734 and CFT073 identified here represent naturally occurring variations in osmotic stress tolerance.

This research was designed to assess the contribution of betaine accumulation mediated by transporters ProP and ProU to the virulence of UPEC. The virulence of bacteria lacking ProP and/or ProU was assessed by examining bacterial growth in urine and applying the murine model for ascending urinary tract infection. In contrast to our previous report on system ProP (Culham et al., 1998), these defects had only minor effects on the recovery of bacteria from murine urine, bladders or 
kidneys, 1 or $3 \mathrm{~d}$ post-transurethral inoculation with either E. coli HU734 or E. coli CFT073 (Table 5; Fig. 6). Since ProP and ProU are the sole mediators of betaine uptake by strain CFT073, we can conclude that betaine accumulation is not essential for colonization of the urinary tract by that organism within this experimental model. The analogous conclusion cannot yet be reached for E. coli HU734 since it retains system BetU. Osmoregulatory betaine accumulation accelerates growth in high-osmolality media (Fig. 1). Betaine accumulation is thus most likely to affect virulence by stimulating bacterial proliferation in the urethra and bladder prior to attachment and invasion of the bladder epithelium (Mulvey et al., 2000; Struve \& Krogfelt, 1999). The requirement for this growth stimulation may be bypassed when bacteria are introduced as a concentrated suspension $\left(10^{9}\right.$ c.f.u. $\left.\mathrm{ml}^{-1}\right)$ to the murine bladder.

Alternative $\sigma$ factor RpoS was of interest during this study because it mediates the transcription of some osmoregulatory genes (Table 1 ) and it is required for the virulence of some pathogens (see Introduction). E. coli HU734, which is less osmotolerant (Fig. 1) and is considered less virulent (Mobley et al., 1993) than E. coli CFT073, expresses a defective RpoS variant (see Figs 1, 2,3 and 4). RpoS activates transcription of 50-100 genes in E. coli $\mathrm{K}-12$ in response to stationary phase, osmotic and other stresses (Ishihama, 2000). In addition, RpoS can inhibit gene expression (Dove et al., 1997; Farewell et al., 1998). Particularly important in the current context is the indirect, negative effect of RpoS on expression of the genes encoding type 1 pili (Dove et al., 1997). In marked contrast to E. coli K-12, both pyelonephritis isolates examined during this study expressed high levels of RpoS during both exponential- and stationary-phase growth (Fig. 2). In view of the contribution of type 1 pili to bladder colonization, it will be interesting to determine whether cystitis isolates of $E$. coli also show high RpoS levels.

The murine model was used to assess the impact of an rpoS deletion on virulence for E. coli CFT073 (Fig. 6). The rpoS lesion had no significant impact on recovery of bacteria from the murine urine, bladders or kidneys 1 or $3 \mathrm{~d}$ post-inoculation. The failure of this lesion to influence urinary tract colonization may reflect the net outcome of both positive and negative perturbations, since RpoS mediates the expression of many genetic loci with known or suspected relevance to urovirulence (e.g. $f i m)$. It is also possible that an effect of the rpoS lesion would be detected during competitive colonization of the urinary tract. For example, an rpoS: :Tn10 insertion conferred a competitive advantage on faecal isolate BJ4 during colonization of the murine intestine (Krogfelt et al., 2000).

\section{ACKNOWLEDGEMENTS}

We are grateful to Gregor Reid for E. coli HU734, to Harry Mobley for E. coli CFT073, to Erhard Bremer for E. coli MC4100 and pOS59, to Regine Hengge-Aronis for E. coli RH90, to David Josephy for E. coli strains GC202, GC4468,
NC202 and NC4468 and for assistance with the catalase assay procedure, to Valerie Robinson and Gary Smith for consultations regarding NMR spectroscopy, to Mikkel Jørgensen for assistance with the urinary tract colonization experiments and to Carsten Struve for discussions of the data. Research support was provided to J.M.W. by the Medical Research Council of Canada (Grant MT-15113).

\section{REFERENCES}

Abee, T. \& Wouters, J. A. (1999). Microbial stress response in minimal processing. Int J Food Microbiol 50, 65-91.

Altman, P. L. (1961). Physical properties and chemical composition of urine: mammals. Part 1: Man. In Blood and Other Bodily Fluids, pp. 363-369. Edited by D. S. Dittmer. Washington, DC: Federation of American Societies for Experimental Biology.

Bergthorsson, U. \& Ochman, H. (1995). Heterogeneity of genome sizes among natural isolates of Escherichia coli. J Bacteriol 177, 5784-5789.

Bergthorsson, U. \& Ochman, H. (1998). Distribution of chromosome length variation in natural isolates of Escherichia coli. Mol Biol Evol 15, 6-16.

Booth, I. R. \& Louis, P. (1999). Managing hypoosmotic stress: aquaporins and mechanosensitive channels in Escherichia coli. Curr Opin Microbiol 2, 166-169.

Brooks, T. \& Keevil, C. W. (1997). A simple artificial urine for the growth of urinary pathogens. Lett Appl Microbiol 24, 203-206.

Brown, E. D. \& Wood, J. M. (1992). Redesigned purification yields a fully functional PutA protein dimer from Escherichia coli. J Biol Chem 267, 13086-13092.

Cairney, J., Booth, I. R. \& Higgins, C. F. (1985). Salmonella typhimurium proP gene encodes a transport system for the osmoprotectant betaine. J Bacteriol 164, 1218-1223.

Casadaban, M. J. (1976). Transposition and fusion of the lac genes to selected promoters in Escherichia coli using bacteriophage lambda and Mu. J Mol Biol 104, 541-555.

Chambers, S. T. \& Kunin, C. M. (1987). Isolation of glycine betaine and proline betaine from human urine. Assessment of their role as osmoprotective agents for bacteria and the kidney. J Clin Invest 79, 731-737.

Chambers, S. T. \& Lever, M. (1996). Betaines and urinary tract infections. Nephron 74, 1-10.

Clare, D. A., Duong, M. N., Darr, D., Archibald, F. \& Fridovich, I. (1984). Effects of molecular oxygen on detection of superoxide radical with nitroblue tetrazolium and on activity stains for catalase. Anal Biochem 140, 532-537.

Culham, D. E. \& Wood, J. M. (2000). An ECOR Group B2- and uropathogen-associated polymorphism in the $r p o S-m u t S$ region of the Escherichia coli chromosome. J Bacteriol 182, 6272-6276.

Culham, D. E., Emmerson, K. S., Lasby, B., Mamelak, D., Steer, B. A., Gyles, C. L., Villarejo, M. \& Wood, J. M. (1994). Genes encoding osmoregulatory proline/glycine betaine transporters and the proline catabolic system are present and expressed in diverse clinical Escherichia coli isolates. Can J Microbiol 40, 397-402.

Culham, D. E., Dalgado, C., Gyles, C. L., Mamelak, D., MacLellan, S. \& Wood, J. M. (1998). Osmoregulatory transporter ProP influences colonization of the urinary tract by Escherichia coli. Microbiology 144, 91-102.

Donnenberg, M. S. \& Kaper, J. B. (1991). Construction of an eae deletion mutant of enteropathogenic Escherichia coli by using a positive-selection suicide vector. Infect Immun 59, 4310-4317.

Donnenberg, M. S. \& Welch, R. A. (1996). Virulence determinants 
of uropathogenic Escherichia coli. In Urinary Tract Infections: Molecular Pathogenesis and Clinical Management, pp. 135-174. Edited by H. L. T. Mobley \& J. W. Warren. Washington, DC: American Society for Microbiology.

Dove, S. L., Smith, S. G. \& Dorman, C. J. (1997). Control of Escherichia coli Type 1 fimbrial gene expression in stationary phase: a negative role for RpoS. Mol Gen Genet 254, 13-20.

Farewell, A., Kvint, K. \& Nyström, T. (1998). Negative regulation by RpoS: a case of sigma factor competition. Mol Microbiol 29, 1039-1051.

Gordon, D. M. \& Riley, M. A. (1992). A theoretical and experimental analysis of bacterial growth in the bladder. Mol Microbiol 6, 555-562.

Grothe, S., Krogsrud, R. L., McClellan, D. J., Milner, J. L. \& Wood, J. M. (1986). Proline transport and osmotic stress response in Escherichia coli K-12. J Bacteriol 166, 253-259.

Guyer, D. M., Kao, J.-S. \& Mobley, H. L. (1998). Genomic analysis of a pathogenicity island in uropathogenic Escherichia coli CFT073: Distribution of homologous sequences among isolates from patients with pyelonephritis, cystitis, and catheterassociated bacteriuria and from fecal samples. Infect Immun 66, 4411-4417.

Haardt, M. \& Bremer, E. (1996). Use of phoA and lacZ fusions to study the membrane topology of ProW, a component of the osmoregulated ProU transport system of Escherichia coli. J Bacteriol 178, 5370-5381.

Hagberg, L., Engberg, I., Freter, R., Lam, J., Olling, S. \& Svanborg Eden, C. (1983a). Ascending, unobstructed urinary tract infection in mice caused by pyelonephritogenic Escherichia coli of human origin. Infect Immun 40, 273-283.

Hagberg, L., Hull, R., Hull, S., Falkow, S., Freter, R. \& Svanborg Eden, C. (1983b). Contribution of adhesion to bacterial persistence in the mouse urinary tract. Infect Immun 40, 265-272.

Hengge-Aronis, R. (1996). Back to log phase: sigma $S$ as a global regulator in the osmotic control of gene expression in Escherichia coli. Mol Microbiol 21, 887-893.

Hengge-Aronis, R., Klein, W., Lange, R., Rimmele, M. \& Boos, W. (1991). Trehalose synthesis genes are controlled by the putative sigma factor encoded by $r p o S$ and are involved in stationaryphase thermotolerance in Escherichia coli. J Bacteriol 173, 7918-7924.

Herrero, M., de Lorenzo, V. \& Timmis, K. N. (1990). Transposon vectors containing non-antibiotic resistance selection markers for cloning and stable chromosomal insertion of foreign genes in gram-negative bacteria. J Bacteriol 172, 6557-6567.

Hvidberg, H., Struve, C., Krogfelt, K. A., Christensen, N., Rasmussen, S. N. \& Frimodt-Moller, N. (2000). Development of a long-term ascending urinary tract infection mouse model for antibiotic treatment studies. Antimicrob Agents Chemother 44, 156-163.

Ishihama, A. (2000). Functional modulation of Escherichia coli RNA polymerase. Annu Rev Microbiol 54, 499-518.

Jishage, M. \& Ishihama, A. (1995). Regulation of RNA polymerase sigma subunit synthesis in Escherichia coli: intracellular levels of $\sigma^{70}$ and $\sigma^{38}$.J Bacteriol 177, 6832-6865.

Jishage, M. \& Ishihama, A. (1997). Variation in RNA polymerase sigma subunit composition within different stocks of Escherichia coli W3110. J Bacteriol 179, 959-963.

Krogfelt, K. A., Poulsen, L. K. \& Molin, S. (1993). Identification of coccoid Escherichia coli BJ4 cells in the large intestine of streptomycin-treated mice. Infect Immun 61, 5029-5034.

Krogfelt, K. A., Hjulgaard, M., Sorensen, K., Cohen, P. S. \&
Givskov, M. (2000). rpoS gene function is a disadvantage for Escherichia coli $\mathrm{BJ} 4$ during competitive colonization of the mouse large intestine. Infect Immun 68, 2518-2524.

Kunin, C. M. (1987). Detection, Prevention and Management of Urinary Tract Infections. Philadelphia, PA: Lea \& Febiger.

Kunin, C. M. (2000). Urinary Tract Infections: Detection, Prevention and Management. Baltimore, MD: Williams \& Wilkins.

Kunin, C. M., Hua, T. H., Van Arsdale White, L. \& Villarejo, M. (1992). Growth of Escherichia coli in human urine: role of salt tolerance and accumulation of glycine betaine. J Infect Dis 166, 1311-1315.

Lange, R. \& Hengge-Aronis, R. (1991). Identification of a central regulator of stationary-phase gene expression in Escherichia coli. Mol Microbiol 5, 49-59.

Lever, M., Sizeland, P. C., Bason, L. M., Hayman, C. M. \& Chambers, S. T. (1994a). Glycine betaine and proline betaine in human blood and urine. Biochim Biophys Acta 1200, 259-264.

Lever, M., Sizeland, P. C., Bason, L. M., Hayman, C. M., Robson, R. A. \& Chambers, S. T. (1994b). Abnormal glycine betaine content of the blood and urine of diabetic and renal patients. Clin Chim Acta 230, 69-79.

Link, A. J., Phillips, D. \& Church, G. M. (1997). Methods for generating precise deletions and insertions in the genome of wildtype Escherichia coli: application to open reading frame characterization. J Bacteriol 179, 6228-6237.

Loeb, W. F. \& Quimby, F. W. (1989). The Clinical Chemistry of Laboratory Animals. New York: Pergamon Press.

Loewen, P. C., Hu, B., Strutinsky, J. \& Sparling, R. (1998). Regulation in the rpoS regulon of Escherichia coli. Can J Microbiol 44, 707-717.

MacMillan, S. V., Alexander, D. A., Culham, D. E., Kunte, H. J., Marshall, E. V., Rochon, D. \& Wood, J. M. (1999). The ion coupling and organic substrate specificities of osmoregulatory transporter ProP in Escherichia coli. Biochim Biophys Acta 1420, 30-44.

Mamelak, D. (1994). The application of genetic and molecular biological techniques to the pyelonephritis isolate Escherichia coli HU734 and colonization studies in the murine urinary tract. MSc thesis, University of Guelph, Canada.

Miller, J. H. (1972). Experiments in Molecular Genetics. Cold Spring Harbor, NY: Cold Spring Harbor Laboratory.

Mobley, H. L., Jarvis, K. G., Elwood, J. P., Whittle, D. I., Lockatell, C. V., Russell, R. G., Johnson, D. E., Donnenberg, M. S. \& Warren, J. W. (1993). Isogenic P-fimbrial deletion mutants of pyelonephritogenic Escherichia coli: the role of alpha Gal(1-4) beta Gal binding in virulence of a wild-type strain. Mol Microbiol 10, 143-155.

Mulvey, M. A., Schilling, J. D., Martinez, J. J. \& Hultgren, S. J. (2000). Bad bugs and beleaguered bladders: Interplay between uropathogenic Escherichia coli and innate host defences. Proc Natl Acad Sci U S A 97, 8829-8835.

Neidhardt, F. C., Bloch, P. L. \& Smith, D. F. (1974). Culture medium for enterobacteria. J Bacteriol 119, 736-747.

Ohnuma, M., Fujita, N., Ishihama, A., Tanaka, K. \& Takahashi, H. (2000). A carboxy-terminal 16-amino-acid region of $\sigma^{38}$ of Escherichia coli is important for transcription under high-salt conditions and sigma activities in vivo. J Bacteriol 182, 4628-4631.

Peddie, B. A., Chambers, S. T. \& Lever, M. (1996). Is the ability of urinary tract pathogens to accumulate glycine betaine a factor in the virulence of pathogenic strains? J Lab Clin Med 128, 417-422.

Price, S. B., Cheng, C. M., Kaspar, C. W., Wright, J. C., DeGraves, F. J., Pehfound, T. A., Castanie-Cornet, M. P. \& Foster, J. W. 
(2000). Role of rpoS in acid resistance and fecal shedding of Escherichia coli O157:H7. Appl Environ Microbiol 66, 632-637.

Rahmatullah, M. \& Boyde, T. R. C. (1980). Improvements in the determination of urea using diacetyl monoxime; methods with and without deproteinization. Clin Chim Acta 107, 3-9.

Randall, K., Lever, M., Peddie, B. A. \& Chambers, S. T. (1996). Natural and synthetic betaines counter the effects of high $\mathrm{NaCl}$ and urea concentrations. Biochim Biophys Acta 1291, 189-194.

Reid, S. D., Hrebelin, C. J., Bumbaugh, A. C., Selander, R. K. \& Whittam, T. S. (2000). Parallel evolution of virulence in pathogenic Escherichia coli. Nature 406, 64-67.

Roberts, J. A., Marklund, B. I., Ilver, D. \& 7 other authors (1994). The Gal $(\alpha 1-4) G$ al-specific tip adhesion of Escherichia coli $\mathrm{P}$ fimbriae is needed for pyelonephritis to occur in the normal urinary tract. Proc Natl Acad Sci US A 91, 11889-11893.

Ross, D. L. \& Neely, A. E. (1983). Textbook of Urinalysis and Bodily Fluids. Norwalk, VA: Appleton Century Crofts.

Sambrook, J., Fritsch, E. F. \& Maniatis, T. (1989). Molecular Cloning: a Laboratory Manual, 2nd edn. Cold Spring Harbor, NY: Cold Spring Harbor Laboratory.

Schellhorn, H. E. \& Hassan, H. M. (1988). Transcriptional regulation of katE in Escherichia coli K-12. J Bacteriol 170, 4286-4292.

Schmidt-Nielsen, B., Graves, B. \& Roth, J. (1983). Water removal and solute additions determining increases in renal medullary osmolality. Am J Physiol 244, F472-F482.

Spector, M. P. (1998). The starvation-stress response (SSR) of Salmonella. Adv Microb Physiol 40, 233-279.
Struve, C. \& Krogfelt, K. A. (1999). In vivo detection of Escherichia coli Type 1 fimbrial expression and phase variation during experimental urinary tract colonization. Microbiology $\mathbf{1 4 5}$, 2683-2690.

Styrvold, O. B., Falkenberg, P., Landfald, B., Eshoo, M. W., Bjørnsen, T. \& Strøm, A. R. (1986). Selection, mapping, and characterization of osmoregulatory mutants of Escherichia coli blocked in the choline-glycine betaine pathway. J Bacteriol 165, 856-863.

Sutherland, L., Cairney, J., Elmore, M. J., Booth, I. R. \& Higgins, C. F. (1986). Osmotic regulation of transcription: induction of the proU betaine transport gene is dependent on accumulation of intracellular potassium. J Bacteriol 168, 805-814.

Wang, Y. \& Kim, K. S. (2000). Effect of rpoS mutations on stressresistance and invasion of brain microvascular endothelial cells in Escherichia coli K1. FEMS Microbiol Lett 182, 241-247.

Waterman, S. R. \& Small, P. L. (1996). Characterization of the acid resistance phenotype and $r p o S$ alleles of shiga-like toxin-producing Escherichia coli. Infect Immun 64, 2808-2811.

Wood, J. M. (1999). Osmosensing by bacteria: signals and membrane-based sensors. Microbiol Mol Biol Rev 63, 230-262.

Zeidel, M. L., Ambudkar, S. V., Smith, B. L. \& Agre, P. (1992). Reconstitution of functional water channels in liposomes containing purified red cell CHIP28 protein. Biochemistry 31, 7436-7440.

Received 12 October 2000; revised 16 January 2001; accepted 31 January 2001. 